\title{
Injuries of the spine sustained during rugby
}

\author{
J. R. Silver MB BS FRCP(Ed)(Lond) \\ National Spinal Injuries Centre, Stoke Mandeville Hospital, Aylesbury, Bucks, UK
}

\begin{abstract}
A comparison was made between the number of rugby injuries seen between 1956 and 1982 (67) and the number of rugby injuries seen between 1982 and 1987 (20). The standards, the positions, the mechanics of injury and the fitness of the players were analysed. It was concluded that the law changes had resulted in a dramatic fall in the number of players injured, that it was the less fit and less skilled players that were getting injured, and that the laws were adequate but were not being enforced.
\end{abstract}

Keywords: Rugby injuries, comparisons and mechanisms of injury

Although numerically few, serious injuries of the spine that give rise to paralysis have attracted considerable attention over the past few years ${ }^{1,2}$. I have been studying the cause, incidence, and possible means of preventing serious injuries of the spine in rugby players since $1972^{3}$. I obtained details of 63 players over the period to 1982 .

These results were presented to the Administrators of the Rugby Union at a joint meeting of doctors, rugby players and administrators in 1983 and as a result a working party was set up to which I was the chief witness. Recommendations were made, initially on an experimental basis, for schoolboys in the UK. These were supported by other unions and particularly by the New Zealand Rugby Football Union and subsequently adopted by the International Board, in an attempt to make the game safer.

The work was brought up to date by studying a further 19 players between 1983 and $1987^{4}$, the majority treated by myself at the National Spinal Injuries Centre. The purpose of this article is to study whether the law changes introduced in 1983, which constituted a controlled experiment in which the players were the subjects, have produced any reduction in the number, type or mechanisms of injury.

\section{Players}

From Table 1 it may be concluded that the distribution is the same. There was a marked drop in the number of schoolboy injuries.

Address for correspondence: Dr J. R. Silver, National Spinal Injuries Centre, Stoke Mandeville Hospital, Mandeville Road, Aylesbury, Bucks HP21 8AL, UK

(C) 1992 Butterworth-Heinemann Ltd 0306-3674/92/040253-06
Table 1. Number and type of player injured and the level of injury between 1956 and 1982 and between 1982 and 1987

\begin{tabular}{|c|c|}
\hline 1956-1982 & $1982-1987$ \\
\hline \begin{aligned} & \multicolumn{2}{l}{ Players injured } \\
& 63 Rugby Union \\
& 2 Rugby League \\
& 2 US Football \end{aligned} & $\begin{array}{l}\text { Players injured } \\
19 \text { Rugby Union }\end{array}$ \\
\hline $\begin{array}{l}67 \text { Total } \\
\text { (One patient injured twice) }\end{array}$ & 19 Total \\
\hline Level of injury & Level of injury \\
\hline $\begin{aligned} 59 & \text { Cervical } \\
1 & \text { Thoracic } \\
& \text { (fell down drunk) }\end{aligned}$ & 18 Cervical \\
\hline $\begin{array}{ll}1 & \text { Malingerer } \\
7 & \text { Unknown }\end{array}$ & 1 Malingerer \\
\hline $\begin{array}{l}\text { Schoolboys } \\
20\end{array}$ & $\begin{array}{l}\text { Schoolboys } \\
3\end{array}$ \\
\hline
\end{tabular}

\section{Standards}

1956-1982

Of the 67 games in which injuries were sustained, three were of first-class standard, 34 were club games, 12 were school team games, four were other school games, and three were practice games; in 11 cases the standard of the game was not known or not relevant.

\section{2-1987}

Only two patients were members of a first-class club and both were playing for their third teams. The rest were second- and third-team players from secondclass clubs. Two were injured in training sessions and two of the three schoolboys were injured in games played against adults.

In conclusion a striking difference between the two periods is evident. From 1956 to 1982 many players were from first-class and school games, whereas in the later period the game was of a lower standard implying less skill.

\section{Players injured in scrums}

Between 1956 and 198215 players were injured in scrums, 14 while playing rugby union and one while playing rugby league. Only one player was a second row forward, which indicates the dangers of playing 


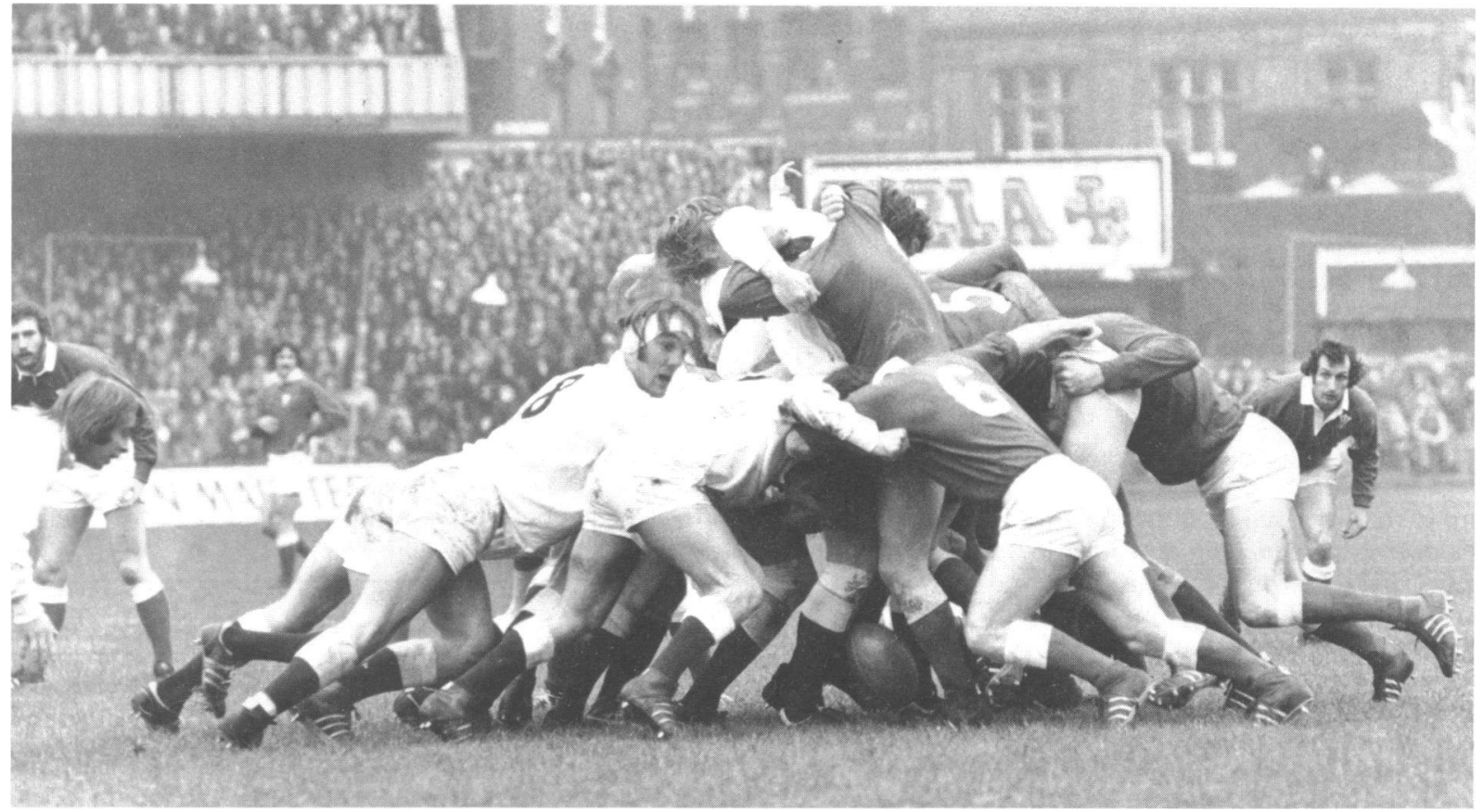

Figure 1. The front rows have been disrupted. Should the second rows continue to push then the front row players are at risk of having their heads driven into the ground. Reproduced with the permission of Colorsport Sports Photographic Agency and Library, London, UK

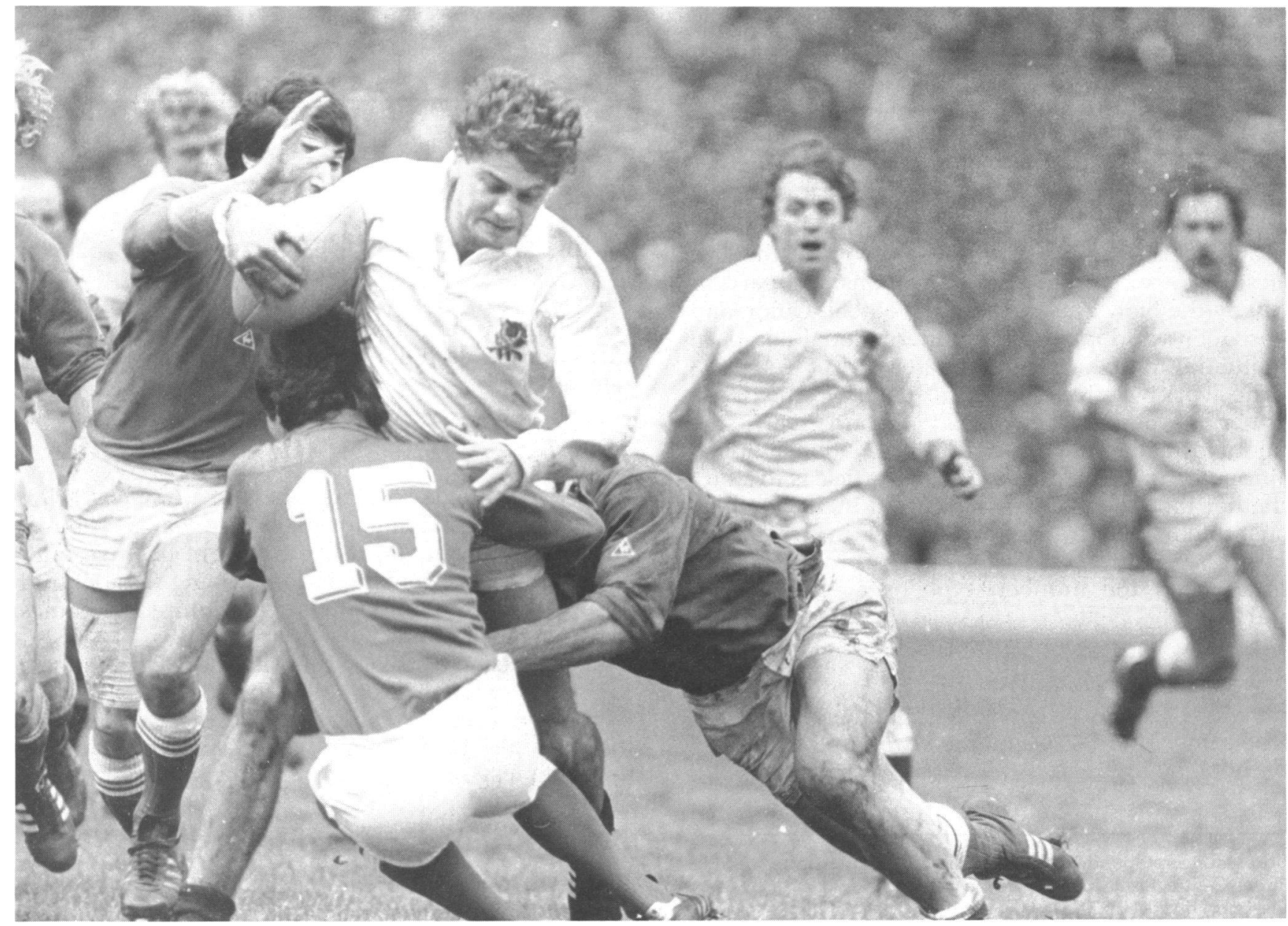

Figure 2. An extremely dangerous situation. Jeavons is being tackled by three people simultaneously and is unable to move away from the tackle. Reproduced with the permission of Colorsport Sports Photographic Agency and Library, London, UK 
in the front row. Three players were injured at the formation of the scrum as a result of extension or forced flexion of the neck, eight were injured when the front row collapsed and the second row continued to push and this fulfils the mechanisms required by Bauze and Ardran ${ }^{5}$ when the head is locked on the ground less force is required to dislocate the neck than if the neck was free. Of the remaining players, two (one of whom was a malingerer) were injured when the scrum collapsed and in the remaining case the mechanism of injury was not known. Collapse of the scrum may be due to a discrepancy of strength and skill or may be deliberate (Figure 1).

Between 1982 and 1987 seven players sustained injuries in scrums. All were front row forwards. One was injured when the players charged at each other in contravention of the laws. Two players were inexpert and had not played in their positions before, or were overmatched. The other cases all followed a collapse of the scrum after which the second rows continued to push. One hooker's shoulder struck the ground. His spine was hyperextended - there was a tearing noise and he experienced a transient paraplegia. No convincing fracture was ever demonstrated. He subsequently also turned out to be a malingerer.
In conclusion, it would appear that the method of injury is unchanged and players are still breaking their necks and are still at risk in the front row.

\section{Players injured in tackle}

Between 1956 and 198214 players were injured when they were tackled while carrying the ball - four of these tackles were illegal. An example of an illegal tackle was when a player was strangled by an opponent who broke his neck in a 'friendly' match. Four players were injured as a result of a multiple tackle (Figure 2). It was not clear in some cases whether the neck was broken in the tackle or in the ensuing pile up. Four players were injured when their heads struck the ground violently. One player speared himself.

Between 1982 and 1987 five players - three forwards and two backs - were injured while tackling. One schoolboy suffered an illegal high tackle, two other players struck their heads while tackling their opponents (Figure 3).

It may be concluded that the mechanism of injury appears unchanged.

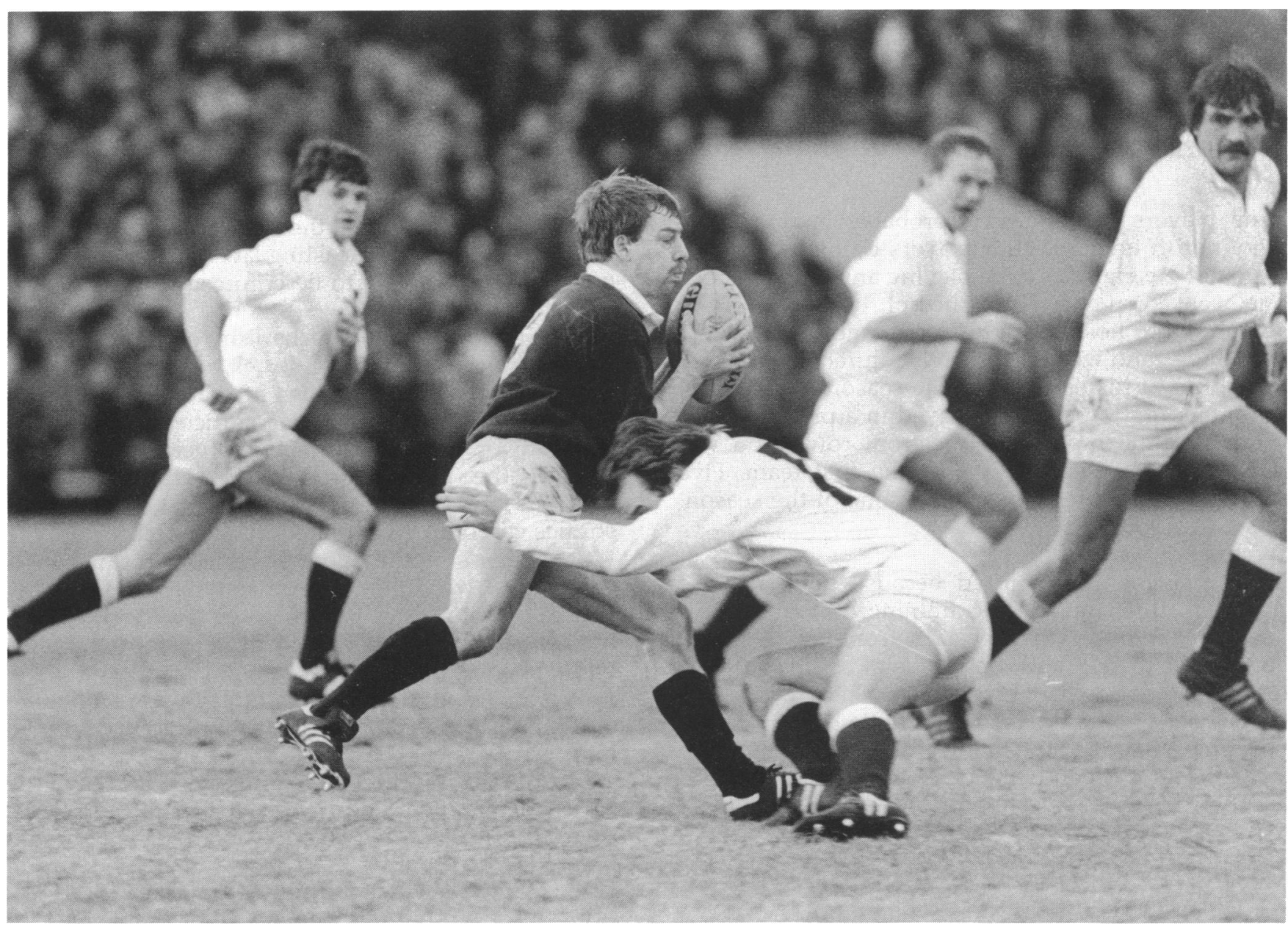

Figure 3. The dangerous tackle. The tackler's head and shoulders are in front of Laidlaw. The tackler's head may be injured as Laidlaw's thigh comes through, sweeping the head up. Reproduced with the permission of Colorsport Sports Photographic Agency and Library, London, UK 


\section{Players injured in ruck and maul}

Between 1956 and 198220 players were injured in a ruck and maul. Of these, 15 were forced to the ground and either their own side continued to push on their buttocks so that their heads were driven into the ground or players piled on top of them in an attempt to kill the ball. One player described how he felt a click as his head struck the ground, followed by severe pain and paralysis as supporting forwards pushed on his buttocks, raising his hips. Two players injured themselves by trying to force their way through other players and striking their heads. One player was kicked and another deliberately strangled. More forwards than other players are injured in rucks and mauls because they actively seek out the ball there. The numbers of injuries incurred in rucks have increased strikingly between 1973 and 1982, none having occurred before 1970 .

Between 1982 and 1987 four forwards and two backs were injured in a ruck and maul. In each case, while stooping to pick up a ball, they were pushed to the ground; other players piled on top and they were driven into the ground while their necks were forcibly flexed.

It may be concluded that the mode of injury appears unchanged and players are still at risk of breaking their necks despite law changes stressing that the shoulder and head must not drop below the waist and emphasizing that players need to stay on their feet.

\section{Fitness}

\section{6-1982}

\section{General}

Nine players were injured probably because they were not fit enough. Four players claimed that they were not generally fit to be playing any kind of sport; one was a patient with schizophrenia, who went straight from hospital to his local rugby club, asked for a game, and was immediately injured. One player turned up at his club before the season had started, not intending to play, and played in a practice game in an unfamiliar position (the front row) on a wet pitch in training shoes against the first team. Five players were injured in the first game of the season.

\section{Specific}

Three players were injured because they had not received sufficient specific training: a wing threequarter was made to play as a front row forward because of his strength and general ability but was unable to cope with the particular skills required; a schoolboy who had played only three or four games of rugby was put in the first team and was injured in a maul and ruck in a match between schools; and another player had played for only half a season.

\section{2-1987}

\section{General}

One player, aged 43 years and who was not fit was injured during a tackle. Another player aged 33 years, who had retired from rugby some two seasons before was at a match to run the line but came on for half a game when a player on his own side went off injured. One other player had been out of the game and had come to referee but was persuaded to play.

This leads to the conclusion that despite the introduction of leagues, competitive rugby and the emphasis on being fit to play, rugby players are still occasionally turning up to play in an unfit state. The importance of being trained for a particular position, especially the front row, is not appreciated in the lower echelons of rugby.

\section{Discussion}

The one player with a thoracic injury received his injury as a result of falling drunk down the stairs after a game. There were two players who feigned paralysis (malingerers) as a result of a collapsed scrum; one, a prisoner, preferred the local prison to $24 \mathrm{~h}$ in the spinal unit, the other made a practice of feigning injury to gain admittance to spinal units throughout the country.

The mechanism of injury was the same, blows to the head, in the scrum, tackle, and maul and ruck, the force being transmitted through the skull to the cervical vertebrae resulting in crushing of vertebrae and extrusion of the vertebral body and disc posteriorly into the cervical canal; extension injury whereby the cord was compressed in extension caused a small number of injuries.

The critical questions that have to be answered are: What is the mechanism of injury? Are the injuries occurring just by bad luck or are they occurring due to technical failure? Are they occurring within the laws of the game or are the failures due to the laws being broken? Are the existing laws adequate? Does it only require the laws to be enforced or do we need new laws?

It is clear that the mechanism of injury is due entirely to the head being struck, or driven into the ground. The other questions are difficult to answer retrospectively as a blow of sufficient violence to dislocate or fracture the cervical vertebrae usually renders the player unconscious. The speed and vigorous impact of the game is such that retrospective studies can only give limited information.

Schneider's methodology in video recording football games ${ }^{6}$ was followed in the study for the Rugby Football Union by Webborn in 19857, Webborn himself had sustained an incomplete tetraplegia while playing rugby.

In many cases slow motion replay was essential to determine the exact mechanism of injury. Of all injuries, $19 \%$ were related to foul play.

Most of the injuries due to foul play occurred in the ruck and maul situation and most of these injuries occurred to back row players who are usually first to break down. The referee was often unsighted during these incidents which led to further injury.

Of the seven injuries due to foul play, five were to the head. Many of the injuries in the tackle clearly occurred because of poor technique by the tackler 
who was as commonly injured as the player tackled. In these few games the scrum was not indicated as the major source of injury. There was, however, the exceptional number of 19 collapsed scrummages out of a total of 39 in one of the games, but fortunately no injuries occurred. In another game as few as three scrummages collapsed. The attitude of the referees to collapse seemed to vary as much as the incidence. In the schoolboy game there were only four injuries and no foul play.

These experimental findings substantiate the laws as being adequate but difficult to enforce, particularly at a junior level. At the school and first-class level there has been a marked reduction in broken necks, but they are still occurring at junior level both in practice and where supervision is inadequate; if violence enters into the game then serious injuries are much more likely to occur. The Webborn findings ${ }^{7}$ show that the head and neck were frequent sources of injury and the mechanism appeared to be identical; any of the collapsed scrums could have resulted in tetraplegia. The greatest difficulty appeared to be in the level of skill in the scrum.

The front row of the scrum is a particularly dangerous place for these injuries to occur as 1-1.5 tons of force is generated there, all impinging upon the props' and hookers' necks in the front row. It is vital that only players who are experienced at playing in the front row of the scrum play there. So if a front row player is injured he is replaced by another experienced front row player, a situation that is easy to achieve at first-class level but even there, replacement of a front row forward by a wing forward has resulted in catastrophe, and the New Zealand Rugby Union has specifically legislated to prevent this happening 8 .

The 16 players must cooperate to keep the scrum on their feet. Since the object of the game is to push and overcome the opponent, this is a prescription for disaster unless the scrums are accurately balanced.

There is a paucity of information about the incidence of these injuries. Comparable figures have come from New Zealand in a series of papers by Burry and Calcinai'. My previous reports had drawn attention to the particular dangers associated with playing in the front row. The paper by Silver and Gill $^{4}$, demonstrates that the danger still continues despite the emphasis on safe scrummaging, as six players have been injured in the front row of the scrum. The one outstanding feature is that in five cases there was a clear infringement of the laws.

The New Zealand experience was similar, and the three methods they used to improve the safety of the game were: to avoid the collision; to avoid the preoccupation with power scrummaging; and to cut down the duration of the scrum by depowering the scrum. As a result the number of injuries has been reduced from an average of nine to six per year (Figure 4).

The number of injuries sustained in the tackle was comparable in the two series and it appeared to be caused by inadequate technique in all cases. One boy was clearly injured in an illegal tackle around the neck. Unfortunately, although attention was drawn to the increase in the number of injuries that had

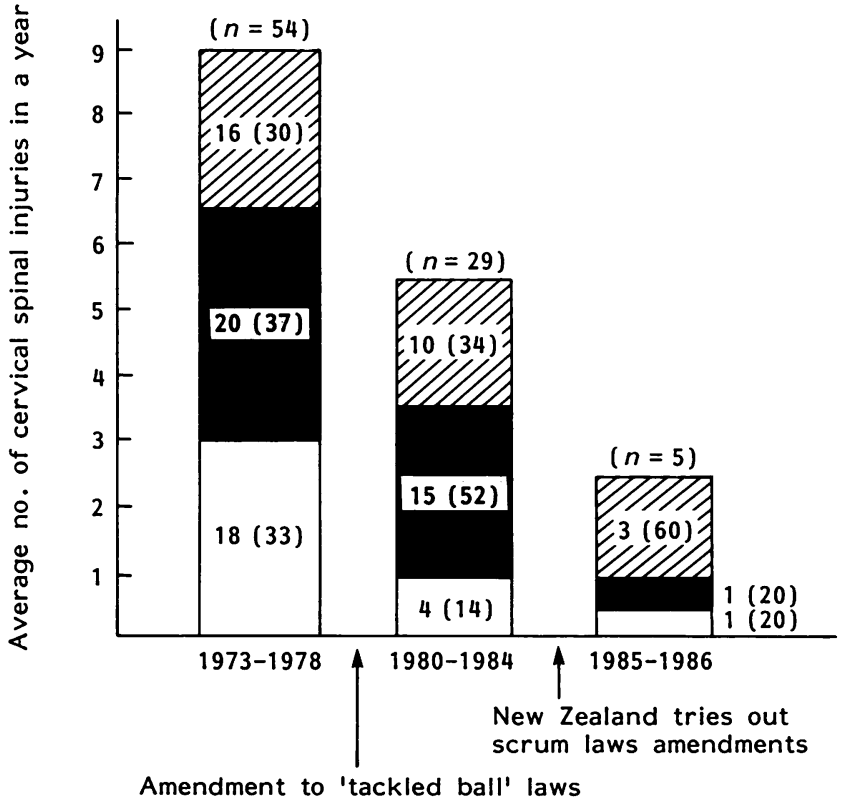

Figure 4. Cervical spine injuries in rugby games in New Zealand. Figures within each bar are average numbers (and percentages) of injuries occurring each year in tackles $(\square)$, scrums $(\square)$, and mauls $(\square)$ in each period

been sustained in the ruck and maul by Silver ${ }^{3}$, these have continued and the mechanism was identical (Figure 5). Players were either pushed to the ground, with or without the ball, after which other players piled on top of them.

It has been suggested that Rugby League is a much safer game as the ruck and maul have been abolished. However, the incidence of injury is four players out of 26000 with broken necks for Rugby League versus five players out of 500000 for Rugby Union, which does not support this claim.

Initially, between 1956 and 1982 it seemed that greater skill did not protect players from injury, but

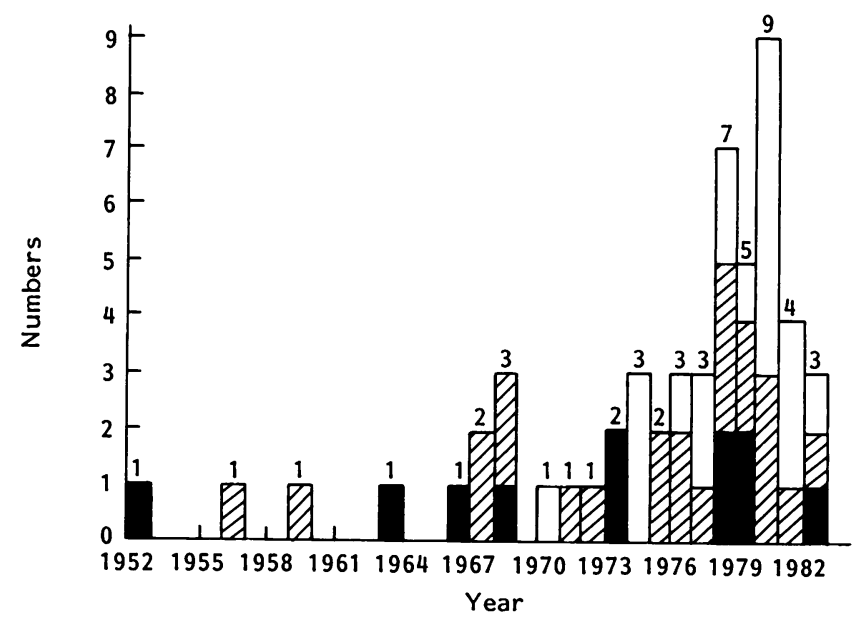

Figure 5. Numbers of injuries occurring in set scrums ( $\square$ ), tackles $(\square)$, and rucks and mauls $(\square)$ in Rugby Union Football by year (figures at the top of each column indicate the total number of such injuries each year). (Year not known for two injuries incurred in scrums and one in a tackle; the hysteric who was injured in a scrum is also omitted.) 
that it was the greater power generated in competitive games allied to the will to win that was the major factor, since injuries occurred to six first-class players in first-class matches and 16 schoolboys in competitive school matches.

The picture changed dramatically between 1982 and $1987^{4}$; only two members of the first-class clubs were injured while playing for the third fifteen, the remainder were playing for second-class clubs in the junior sides of the lower fifteens. Only three were schoolboys, two were injured while playing against adults, a situation specifically discouraged because of the recognized dangers inherent in the mismatch of strength and skill.

In England and Wales there is a long tradition of rugby and experienced players and teachers of the game in private schools, although in the state sector there is a problem with a lack of masters who are versed in the game to teach the laws and techniques to players. Rugby is intrinsically dangerous, the greatest care must be taken in teaching and supervising how the game is played. There does appear to be an undue incidence of rugby injury in Canada since Sovio et al. ${ }^{10}$ reported nine out of 390 admissions to a spinal unit in Canada with serious neurological deficit, five as a result of collapse in the scrum and four in other ways. The mechanisms appeared to be identical, but as there is only a small rugby playing population in British Columbia, 9000, the incidence appeared to be higher than in other countries, which would seem to indicate that the game is a cause for concern.

It would appear that there has been a decline in the incidence of serious injury in the UK and New Zealand because of the changes in the laws of rugby.

\section{References}

1 Scher AT. Rugby injuries to the cervical spinal cord. $S$ Afr Med J 1977; 51: 473-5.

2 Williams JPR, McKibbin B. Cervical spine injuries in Rugby Union Football. Br Med J 1978; 2: 23-30.

3 Silver JR. Injuries of the spine sustained in rugby. $\mathrm{Br}$ Med J 1984; 228: 37-43.

4 Silver JR, Gill S. Injuries of the spine sustained during rugby. Sports Med 1988; 5: 328-34.

5 Bauze RJ, Ardran GM. Experimental production of forward dislocation in the human cervical spine. J Bone Joint Surg $[\mathrm{Br}]$ 1978; 60-B: 239-45.

6 Schneider RC. Mechanisms of injury. In: Schneider RC ed. Head and Neck Injuries in Football. Baltimore: Williams and Wilkins, 1973.

7 Webborn ADJ. Rugby Injuries Study, Pilot Scheme - report for May 1985, 1354-70.

8 The New Zealand Rugby Football Union Circular No: 88/196, October 1988.

9 Burry HC, Calcinai CJ. The need to make rugby safer. $\mathrm{Br} \mathrm{Med} \mathrm{J}$ 1988; 296: 149-50.

10 Sovio OM, Van Peteghem PK, Schweigel JF. Cervical spine injuries in rugby players. Can Med Assoc J 1984; 130: 735-6. 